\title{
Exploring impression management tactics within the Afrikaans Coloured culture in a formal setting
}

\begin{tabular}{|c|c|}
\hline \multicolumn{2}{|c|}{$\begin{array}{l}\text { Authors: } \\
\text { Lauren Delport }^{1} \text { iD } \\
\text { Nontsikelelo D.P. }^{\text {Mtshelwane }}{ }^{1} \text { (D) } \\
\text { Lizelle Rossouw }^{1} \text { id }\end{array}$} \\
\hline \multicolumn{2}{|c|}{$\begin{array}{l}\text { Affiliations: } \\
{ }^{1} \text { School of Industrial } \\
\text { Psychology and Human } \\
\text { Resource Management, } \\
\text { Faculty of Economic } \\
\text { Management Sciences, } \\
\text { North-West University, } \\
\text { Potchefstroom, South Africa }\end{array}$} \\
\hline \multicolumn{2}{|c|}{$\begin{array}{l}\text { Corresponding author: } \\
\text { Nontsikelelo D.P. } \\
\text { Mtshelwane, } \\
\text { debbie.mtshelwane@nwu. } \\
\text { ac.za }\end{array}$} \\
\hline \multicolumn{2}{|c|}{$\begin{array}{l}\text { Dates: } \\
\text { Received: } 28 \text { Aug. } 2021 \\
\text { Accepted: } 05 \text { Jan. } 2022 \\
\text { Published: } 25 \text { Feb. } 2022\end{array}$} \\
\hline \multicolumn{2}{|c|}{$\begin{array}{l}\text { How to cite this article: } \\
\text { Delport, L., Mtshelwane, } \\
\text { N.D.P., \& Rossouw, L. (2022). } \\
\text { Exploring impression } \\
\text { management tactics within } \\
\text { the Afrikaans Coloured } \\
\text { culture in a formal setting. SA } \\
\text { Journal of Industrial } \\
\text { Psychology/SA Tydskrif vir } \\
\text { Bedryfsielkunde, 48(0), } \\
\text { a1932. https://doi.org/ } \\
\text { 10.4102/sajip.v48i0.1932 }\end{array}$} \\
\hline \multicolumn{2}{|c|}{$\begin{array}{l}\text { Copyright: } \\
\text { (C) 2022. The Authors } \\
\text { Licensee: AOSIS. This } \\
\text { is licensed under the } \\
\text { Creative Commons } \\
\text { Attribution License. }\end{array}$} \\
\hline \multicolumn{2}{|l|}{ Read online: } \\
\hline 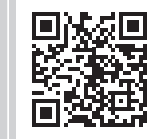 & $\begin{array}{l}\text { Scan this QR } \\
\text { code with your } \\
\text { smart phone or } \\
\text { mobile device } \\
\text { to read online. }\end{array}$ \\
\hline
\end{tabular}

Orientation: Impression management (IM) tactics are displayed by Afrikaans Coloured individuals in formal settings. The formal setting (workplace) entails interactions with colleagues and supervisors.

Research purpose: Explore and identify IM tactics displayed in the Afrikaans Coloured culture in a formal setting.

Motivation for the study: This study forms part of a bigger research project where research has been conducted on different cultural groups (e.g. White Afrikaans, Zulu and Tswana) in order to develop a social desirable measuring instrument specifically for the South African context.

Research approach, design and method: A qualitative research design was utilised based on a phenomenological approach, following an emic perspective. The sample consisted of $(n=11)$ Afrikaans Coloured individuals, with a tertiary qualification within South African organisations that comprised employees more than 50 people, situated in the Western Cape and Northern Cape provinces. For data collection, semi-structured interviews were conducted. Qualitative data analysis steps of Creswell was used to analyse data.

Main findings: Results indicate that Africans Coloured individuals use different tactics when impressing colleagues and supervisors in the workplace.

Practical/managerial implications: This study provides the management of organisations the essential knowledge on the IM tactics that Afrikaans Coloured employees display in a formal setting.

Contribution/value-add: This study contributed to the body of knowledge regarding IM tactics that Afrikaans Coloured employees display. This study might enable organisations to better understand and manage individuals from this cultural group.

Keywords: impression management; Afrikaans Coloured culture; social constructivism; emic perspective; formal setting.

\section{Introduction}

When individuals interact with other individuals in a social setting, there's a tendency of displaying particular behaviours and they tend to assume beliefs of people, based on their interaction, knowledge and understanding built around certain situations (Leary \& Tangley, 2012). Adopted behaviours from various social interactions lead to form a certain perspective and opinion amongst individuals, prior to familiarising themselves with the content of a situation. The social context that influences an individual's behaviour is usually because of an individual's different needs, specifically the need to belong, the need to retain self-esteem, the need to exercise control over an individual's reactions and the need to feel that one has a meaningful existence (Rebello, Burton, Heiman, \& Greenway, 2015). Impression management (IM) is when people behave in a certain manner in different situations to shape or influence other people's perspectives (Bourdage, Wiltshire, \& Lee, 2015). When individuals display certain types of behaviour, certain IM tactics become evident, depending on the situation. People care about how others perceive them, which is a critical factor for an organisation and in the general social setting (Bolino, Long, \& Turnley, 2016). According to Bolino et al. (2016), IM by groups could have implications on the organisational resources that are allocated and the perceptions of organisational policies.

When individuals are in the workplace, IM can be used intentionally and strategically, employees may consciously create a specific image, such as likeability, and competence amongst employees 
(Jones \& Pittman, 1982). When interacting in a formal setting, one needs to understand employees' behaviour that they display towards their colleagues, management and clients (Clegg, Kornberger, \& Pitsis, 2016). The formal setting creates a framework for the individual's behaviour at a professional level, as it is appropriate to make a good impression on your colleagues (Choi, Moon, \& Chun, 2015). Impression management behaviour displayed by employees may have implications on their performance or their performance is perceived by others and actions when seeking information or providing feedback (Bolino et al., 2016). For example, in a formal setting, the employees' willingness to speak up depends on whether they are concerned about the image they portray to other employees or what others will think of their opinion.

In a formal setting, individuals encounter employees from different cultural backgrounds that have different norms and values. In South Africa, managing various employees from different cultural backgrounds in a work setting may cause many obstacles in the areas of communication and collaboration in the workplace (Hussain, 2018). Furthermore, one of the challenges that might occur in managing diverse groups in the workplace includes the differences in the language usage of cultures.

The use of IM tactics is not always positive. Some individuals utilise IM tactics strategically for their own benefit. Tactics displayed can include the following: ingratiation (displaying likeable behaviour); intimidation (displaying behaviour in order to be perceived as powerful); self-promotion (displaying overly competent behaviour); exemplification (displaying moral worthiness and integrity) and supplication (displaying one's weaknesses in order to gain sympathy; Jones \& Pittman, 1982). In a study conducted by Gwal (2015) amongst academics, it was found that employees mostly make use of ingratiation by showing appreciation to their colleagues for their achievements. Although IM is sometimes conceptualised as controlling or misled behaviour, researchers have argued that IM does not essentially reveal that employees are creating incorrect impressions or acting in an unfavourable manner (Bolino et al., 2016). Research by Dondolo and Chinyamurindi (2018) found that when an individual is going through a job interview, he/she may portray the perfect behaviour and attitudes for the panel to fit into the organisation's values, but display only this behaviour to obtain the panel's acceptance and trust. The individual convinces the panel through IM behaviours that he/she is suitable for the relevant position and situation. Using IM behaviours appropriately in a unique situation is important, as it can be interpreted as inappropriate behaviour as perceived above (Bott \& Spillius, 2014). The quality and decisions made by human resource (HR) personnel specifically when it comes to recruitment and selection are impacted by the IM behaviour that employees display (Dondolo \& Chinyamurindi, 2018).
Opposite the positive intentions of IM tactics, it may be expected in an organisational setting that one behaves in a manner that is deemed unfavourable in your culture, which might contribute towards losing one's own sense of identity and beliefs (Melloni, Stacchezzini, \& Lai, 2015). It is, therefore, key that in a professional, but diverse environment, employees be granted the opportunity to be themselves. This means that employees should be able to be themselves, without losing sight of their core values and beliefs. Conformity, excuses, apologies, self-promotion, flattery, favours and association are perceived as being the most common IM tactics employed within organisations (Gardner \& Martinko, 1988). Different IM tactics can be employed in order to be viewed as favourable within the formal setting. These tactics include amongst others, agreeableness, highlighting one's strengths and downplaying one's weaknesses, assuming accountability, making excuses and doing favours for others (Gwal, 2015; Malham \& Saucier, 2016). Seeing that there are many IM tactics evident within the formal setting, the receiver (i.e. fellow colleagues and employers) may not be able to distinguish between authentic behaviour and IM tactics, thereby not having a true reflection of the individual employee. The types of IM tactics individuals utilise depend on their environment they find themselves in. This suggests that when functioning in a formal setting where individuals interact with colleagues and superiors, they feel the need to be in line with the organisation's values and norms, contributing to the organisation's objectives and achievements (Saxena, 2014).

For organisations to increase productivity and cultivate good relations amongst employees, different cultures should be explored and behaviours need to be understood within the cultural group. The research of Kemp (2013) on the white Afrikaans group (WAG) and the research of Mtshelwane (2015) on the Zulu culture in South Africa explored social desirability and IM, the uniqueness of the cultures and how each of these cultures, respectively, add value to the South African workplace. Although several research studies have been conducted on IM, limited research has been conducted on IM in South Africa regarding the Afrikaans Coloured culture.

The Coloured culture has an incredibly diverse heritage (Adhikiri, 2008) as this group of people may adopt behaviour and beliefs from other dominant cultural groups in South Africa, depending on the setting they are functioning in. Because of the confusion and the lack of knowledge pertaining to their own culture, the Afrikaans Coloured culture has a propensity to merge into other cultures when functioning in different settings (Palmer, 2015). The understanding of diverse cultural groups is essential in the workplace to establish a cooperative culture amongst employees. The lack of literature regarding the Afrikaans Coloured culture in South Africa necessitates the current research to enable employees in the workplace to understand IM tactics amongst Coloured people when interacting in a formal setting. 


\section{Research purpose and objectives}

The objective of this article was to explore IM tactics that are utilised by individuals in the Afrikaans Coloured culture in the workplace. The objectives of this study were specifically (1) to identify IM tactics displayed towards colleagues in a formal setting and (2) to identify IM tactics displayed towards supervisors in a formal setting.

\section{Literature review Impression management}

Impression management refers to individuals' behaviours displayed, with the aim to influence the perceptions that others might have about them (Feldman, 2011). Impression management also involves adapting to non-verbal prompts such as facial expressions, smile, eye contact, physical closeness and touching. These non-verbal prompts also have different meanings in each culture (Spong \& Kamau, 2012). These behaviours are very similar as individuals need know when and how to use IM tactics. With IM, one's intrinsic motivation is often used. Brouer, Gallagher and Badawy (2016) describe this as a conscious or unconscious process in which individuals attempt to influence the views of other people about a person, object or event.

When utilising IM tactics in a conscious process, people can see the use of IM tactics as a negative intention, because behaviours may be consciously manipulative and deceptive (Kemp, 2013). People will use tactics by claiming intentionally to have positive attributes they know they do not usually have. Furthermore, these individuals will also deny or downplay negative attributes, as they know they have to impress those around them (Holtgraves, 2004).

\section{Impression tactics in a formal setting}

A formal setting constitutes a person's professional environment or work life. Impression management tactics in this setting can be used intentionally and strategically, as employees may consciously seek to encourage a specific image, for example, likeability, competence and neediness amongst other employees (Jones \& Pittman, 1982). When a formal environment is explored, employees often tend to adjust their working hours, dress code and timely communication expectations, so other employees could be impressed by the behaviour they display (Anjum \& Shah, 2017). Self-promotion and flattery are often used as IM tactics by employees to favour themselves at work, by creating a buzz about their tasks completed and praising themselves when management compliments their work. Employees using these tactics also accept compliments and acceptance from other employees differently (Merdin, 2011). Impression management tactics displayed in a formal setting are when you are trying to focus on impressing your colleagues by displaying openness, reassuring people to trust you and feeling comfortable working with you (Mtshelwane, 2015).

In this study, the researcher explored the various IM tactics utilised in the Afrikaans Coloured culture from various individuals in a formal setting.

\section{Research design Research approach}

The research study followed a qualitative approach from the social constructivism paradigm. The research objectives were explored through the research study in accordance with the social constructivism paradigm using the emic perspective. The emic perspective places a focus on the cultural insider's view (Morris, Leung, Ames, \& Lickel, 1999). The aim was to gather in-depth insight into lived experiences and information that translate into data regarding IM within the Afrikaans Coloured culture. Amineh and Asl (2015) describe social constructivism as a knowledge and communication theory probing the knowledge and understanding of the world that is developed mutually by people. The research objective in this study was to explore IM tactics used in the Afrikaans Coloured culture when impressing others in a formal setting. Therefore, during the semi-structured interviews, participants projected their own meaning, reality, understanding and experiences.

\section{Research strategy}

The researcher followed a qualitative descriptive strategy in this research study. The purpose was to gain in-depth, rich and relevant data directly from individuals experiencing this phenomenon being investigated (Neergaard, Olesen, Anderson, \& Sondergaard, 2009). This objective was reached by analysing and interpreting meaning of IM tactics as attributed to by the participants (Larson \& Bradshaw, 2017).

\section{Research method}

\section{Research setting}

Permission to conduct the research study was granted by organisations situated in the Western and Northern Cape provinces. According to Stats SA (2019), the Coloured culture is the second largest population group in South Africa, comprising $8.8 \%$ of the population. Research participants were employees working in the selected organisations and belonging to the Afrikaans Coloured culture. Interviews were conducted in either a boardroom or office of respective organisations, where it took $30 \mathrm{~min}$ to conduct each interview.

\section{Entrée and establishing researcher roles}

Several roles were fulfilled by the researcher, including the planner of the research study, the data collector, transcriber and analyser of data, and the writer of the report. Once permission was granted, research participants were contacted and interview dates were scheduled. During the interviews, participants were reassured of confidentiality, and were issued a consent form and it was made clear that being part of the study was voluntary and participants could withdraw from the study at any given time. The researcher transcribed and analysed the data that were collected. The analysed data were checked by the co-coder to ensure that findings are a true reflection of the data collected. 


\section{Research participants and sampling methods}

The researcher made use of purposive sampling methods during the data collection. Purposive sampling was used to reflect the particular features of a selected group within the sample population (Foxcroft \& Roodt, 2013). In the beginning phase of the research study, the researcher intended to interview 15 participants, however data saturation was reached sooner and interviews were concluded with a total of 11 participants.

The participants had to meet the following criteria: (1) They must be full-time employees; (2) they must be Afrikaansspeaking individuals and (3) must be employees from the Western or Northern Cape.

Table 1 provides the characteristics of participants, as discussed above, which forms the sample of this study.

Of the total participants, $45 \%$ of them were between the age of 26 and 30 years, $27 \%$ of them were between 31 and 35 years and $18 \%$ of them were between 24 and 25 years of age. A small number of participants were older than 41 years of age. The majority of the participants were male $(64 \%)$, whilst $36 \%$ of them were females. All participants were Afrikaans speaking Coloured employees who have already obtained a tertiary qualification, as this was part of the criteria for the sample of the targeted participants in the research study.

\section{Data collection methods}

Data were collected through semi-structured interviews. Although during an interview, a set of questions was asked to all participants, the researcher also probed to collect rich and informative data. Before the interviews commenced, research participants were made aware that the interviews were recorded to ensure that all the information is captured. A consent form was discussed in detail with participants, which the participants had to sign and familiarise himself or herself with before moving on to the questions.

All participants were asked the same questions as stated below:

\begin{tabular}{lccc}
\multicolumn{4}{l}{ TABLE 1: Characteristics of participants $(N=11)$. } \\
\hline Item & Category & Frequency $(f)$ & Percentage (\%) \\
\hline Age & $20-25$ & 2 & 18.0 \\
& $26-30$ & 5 & 45.0 \\
& $31-40$ & 3 & 27.0 \\
Gender & $41>$ & 1 & 10.0 \\
& Female & 4 & 36.0 \\
Language & Male & 7 & 64.0 \\
Race & Afrikaans & 11 & 100 \\
Highest level of qualification & Coloured & 11 & 100 \\
& Higher education & 11 & 100 \\
Province & and training & & \\
& Western Cape & 6 & 55 \\
\hline
\end{tabular}

- 'Which impression management tactics would you display in order to impress colleagues at your work?'

- 'Which impression management tactics would you display in order to impress your supervisor/mentor/ manager?'

\section{Recording of data}

Prior the interviews, the participants were informed that a digital voice recorder will be used to help with the data analysis later on. This helped the interviewer to capture the exact words of the participants. On the completion of the interviews, the data were transcribed in an Excel spreadsheet that was password protected. The researcher ensured that the data were kept safe at all times by using a passwordprotected system. The researcher and the supervisors, who acted as the co-coders, were the only people who had access to the password and voice recordings.

\section{Data analysis}

In order to analyse the data of this research study, the qualitative data analysis steps of Creswell (2014) will be followed:

\section{Step 1}

During this step, interviews were captured on an Excel sheet. The data were scanned in order to form a general and overall view of the collected data.

\section{Step 2}

Here, the researcher identified general ideas and impressions as deduced from the raw data. These ideas and impressions are noted in order to form a more detailed picture of the collected data.

\section{Step 3}

In this step, the researcher started with the coding process. This process entails that parts of the data will be grouped together and assigned with a name (i.e. code) or category, thus, grouping similar ideas together and naming them. It is important to note that codes can be assigned to data in various ways: (1) codes can be developed based on information that emerged from participants when data were collected; (2) the researcher can decide to make use of predetermined codes or (3) the researcher can decide to make use of both predetermined and emerging codes. The researcher decided to code the data according to the research objectives (which is also in line with the interview questions). Therefore, two codes were extracted (i.e. IM tactics displayed towards superiors and IM tactics displayed towards colleagues).

\section{Step 4}

The codes created in step 3 were used to develop and describe themes. These themes were reported as the main findings of this study. These themes were supported by direct quotes 
from the participants. From the findings, it was seen that some of the themes were evident in both codes. Code 1 produced five themes and code 2 produced four themes.

\section{Step 5}

During this step, the themes developed and described in step 4 were presented in a manner that is understandable to the reader.

\section{Step 6}

Lastly, the researcher interpreted the findings. Here, the researcher decided on the manner in which the findings of the study should be reported. In the 'discussion' section, the results of the study were explained and substantiated by literature.

\section{Strategies employed to ensure quality data}

To ensure that the findings were trustworthy, the researcher adhered to a specific criteria.

\section{Credibility}

Credibility refers to the overall belief of a study or the degree to which the research outcomes seem accurate based on the research process that has been followed (De Vos, Strydom, Schulze, \& Patel, 2011). To ensure the credibility of the data, co-coders were used in the study, who are registered professional, academic staff of the North-West University (NWU). The researcher and the co-coders analysed and coded the data. The responses of the participants were also included in the findings section of the study. The researcher also ensured credibility by providing direct quotes of the participants to substantiate extracted themes.

\section{Transferability}

Transferability indicates the degree of content and data of this study that can be repeated in other settings (De Wet, 2016). The researcher provided a thick description of the study details. The researcher investigated and interpreted the findings of the research by defining the objectives clearly to ensure that the study could be used for future research purposes.

\section{Dependability}

Dependability indicates that the research process is rational, well-documented and audited, which can be seen for reliability as well (Bryman \& Bell, 2015). To ensure dependability, the researcher asked the same questions to all participants and provided the same information to participants. The process was documented, indicating the decisions that were made and how the interpretation and coding were done.

\section{Confirmability}

Confirmability can relate to the accurate reflections of participant's perceptions without researchers' views interfering with the findings (Nieuwenhuis, 2016). The researchers must also be aware of their own predispositions before commencing with the research and interacting with the participants. Therefore, the researcher ensured that all responses were captured exactly as the participants responded and told the participants to elaborate on responses they provided.

\section{Reporting style}

A narrative reporting style was utilised in this study. Findings were supported by direct responses from the participants, providing the assurance that the results were reported truthfully. Afrikaans quotes were translated into English by an accredited language practitioner in order to accommodate diverse language groups and achieve the objectives of this study.

\section{Ethical considerations}

The research study was approved by the research committee in the relevant research entity of the NWU. After the proposed research study was approved, ethical clearance was granted through an ethics process by the NWU-EMELTEN-REC (Education, Management and Economic Sciences, Law, Theology, Engineering and Natural Sciences Research Ethics Committee) (NWU 00255-18-A2). The researcher undertook an ethical obligation to ensure that no harm can be done to the participants for voluntary participation in the research study. Research participants who took part in this study provided informed consent to the researcher. Also, personal information was kept anonymous and they were also informed that they could withdraw from the study if they chose to do so.

\section{Findings}

Following is a detailed description of the findings of the current research study.

\section{Impression management tactics displayed towards superiors and colleagues in a formal setting}

In this section, all IM tactics that Afrikaans Coloured employees display when impressing their superiors and colleagues at work are discussed.

Be a good colleague. This is a tactic displayed to impress colleagues only. This can be done by showing interest in your colleagues and complimenting them for good work. Furthermore, putting effort into effectively interacting with colleagues shows that you are a good co-worker. To make special and extra effort for colleagues is also regarded as important. Supporting your colleagues, and valuing their opinions and feelings are also regarded as important:

\footnotetext{
'The use of your social interpersonal tactics to be able to interact with anyone at work or on a social level.' (Participant 1)

'To go the extra mile for people is an important characteristic that you should show.' (Participant 2)

'To flatter other people with compliments. If your colleague does a presentation, flatter them with compliments and how they handle difficult situations.' (Participant 10)
} 
'To always considering opinions, feelings, emotions towards a certain situation. I will always use democratic skills people's to give guidance and support to colleagues.' (Participant 1)

'Always try and get most of the colleagues input and try to get the relevant colleagues involved. Let colleagues feel valued and involved.' (Participant 8)

Be true to yourself. Being true to oneself is also a tactic used to impress colleagues only. This means that you always behave in a manner that is true to yourself. Furthermore, be yourself by not acting inferior to your colleagues:

'Be who you are, other people will be impressed by your personality or not.' (Participant 11)

'Every individual has his/her own talents, embrace it, so never feel less valued or inferior to others. Never back down for other people that let you feel inferior to them.' (Participant 6)

Be hard-working: This tactic is used to impress both supervisors and colleagues. This means that you always do your work correctly and show that you are a hard worker. This includes being proud of the work that you do and showing you have good problem-solving skills. By going the extra mile for people at work might also impress them:

'Your work should do the talking and impress people ... show pride in your work and people how it can be done.' (Participant 4)

'You have to impress other cultures with your hard work ....' (Participant 6)

'... You prove yourself in your work you do, you always do your work correct and work hard.' (Participant 11)

'We all know your reputation speaks for itself through your work, but only to a certain point, as you always have to work extra harder to impress the management.' (Participant 4)

'Show the people that you work with, that you are hard-working and always willing to go the extra mile for people.' (Participant 9)

Display professional behaviour. This tactic is also employed to impress both superiors and colleagues within an informal setting. This means that you should always behave in a professional manner at work and put your best foot forward. This can be achieved by respecting the values of the organisation and showing a good work ethic and not gossiping about co-workers. Behaving in a professional manner shows respect and courtesy towards your colleagues, clients and all other stakeholders. Professionalism at work is also displayed by showing good time management skills, work ethics and following the protocols and guidelines of the organisation:

'You have to adapt to what the organisation believes in, as this is not always how you are or what you believe in.' (Participant 3)

'You must always show professional behaviour and communication and keep the professional line at work towards your colleagues.' (Participant 9)

'Always be on time, manage your time effectively, show professional behaviour and when communicating with others in the workplace.' (Participant 3)
'Always put the best foot forward as to your manners and work ethics.' (Participant 4)

'You must follow guidelines to show your work ethics in a positive way, showing management you adhere to the organisations guidelines.' (Participant 11)

Display your uniqueness: This tactic is utilised to impress one's superiors only. This means that you show the management the way you can contribute to the workplace by displaying your unique characteristics:

'You must remember to always bring out your uniqueness in what you do and how you do it - with this management will be impressed as they will see how you bring your personality into your work.' (Participant 8)

'The most important thing for me to display is to get out of your comfort zone, as this is the way to show your uniqueness to people and what you are capable of doing.' (Participant 9)

Raise your opinion: This is a tactic used to impress superiors only. It is important to raise your opinion when necessary in the workplace. This shows that you are not inferior to others. Also, give your opinion on matters when engaging in conversations with management:

'Always make sure you can add valuable information to a conversation by always keeping up to date with what's going on in the news.' (Participant 7)

'Many people feel scared to raise their opinion when working under certain management, but I have learned to raise my opinion ....' (Participant 2)

'Raise your opinion when necessary when in a conversation or discussion regarding a certain topic, do not be afraid to say what you think.' (Participant 11)

\section{Discussion}

The general objective of this study was to explore IM tactics within the Afrikaans Coloured culture in a formal setting amongst colleagues and superiors.

\section{Impression management tactics displayed towards superiors and colleagues}

From the results, it became evident in some instances that the same tactics are employed to impress both superiors and colleagues. These tactics included being hard-working and displaying professional behaviour. Being hard-working was an IM tactic used by Afrikaans Coloured individuals to impress both colleagues and superiors. Being hard-working can be classified by Jones and Pittman (1982) as one of the categories of IM, namely, exemplification. Exemplification refers to displaying behaviour in order to be seen as hardworking and dedicated (Jones \& Pittman, 1982; Korzynski, Haenlein, \& Rautiainen, 2021), which in turn may improve one's reputation amongst important others (Korzynski et al., 2021).

As mentioned, displaying professional behaviour is another tactic used to impress superiors and colleagues. By showing professionalism, you respect the values of the organisation 
and show a good work ethic. McQuerrey (2019) argues that professionalism in the workplace can be preserved if owners and managers of organisations established clear guidelines on how employees should behave in an acceptable and professional manner. According to Scott (2019), when one shows a professional attitude at work, it not only increases productivity amongst employees, but also allows employees to be proud of their work and in the long-term also ensures the success of the organisation. When an employee is viewed as being professional(especially, within white-collaroccupations), it may lead to various positive outcomes such as being treated with respect, being viewed as someone with status and power and it also provided more networking opportunities (Ibarra, 1995; McCluney, Durkee, Smith, Robotham, \& Lee, 2021; Pratt, Rockmann, \& Kaufmann, 2006; Roberts, 2005). It is, therefore, not surprising that this is regarded as an IM tactic to impress both colleagues and superiors.

\section{Impression management tactics displayed towards superiors}

Raising your opinion was a theme mentioned by participants as a tactic to impress superiors. According to Edmondson and Besieux (2021), raising one's opinion can be both good or bad, depending on the underlying intent and manner in which the opinion was raised. Encouraging quality conversations within organisations is especially important in current diverse organisations and enhances organisational effectiveness (Edmonds \& Besieux, 2021; Martin, 2014). This is, therefore, a tactic that this culture group can make use that can benefit the organisation.

Displaying your uniqueness was another tactic used to impress one's superior. Showing one's uniqueness may also lead to beneficial outcomes within the work environment. When displaying one's uniqueness in the workplace, one's colleagues and superiors may recognise how you can contribute to the shared goals of the organisation and may, therefore, require of you to do so (David, Kim, Farh, Lin, \& Zhou, 2021).

\section{Impression management displayed towards colleagues}

Being true to yourself was an IM tactic utilised by Afrikaans Coloured culture in order to impress colleagues. This can also be referred to as self-verification. According to Cable and Kay (2012), self-verification refers to behaving in a manner that is truthful in order for others to see who you really are. When engaging in professional relationships, such individuals (i.e. high in self-verification striving) try to show their real personality and styles of working (David et al., 2021).

Being a good colleague was also regarded as being important tactic to display to colleagues. A good colleague refers to displaying behaviour such as complimenting colleagues, doing favours for them and going the extra mile. According to Jones and Pittman (1982), this can be classified as an IM tactic named ingratiation and refers to doing favours for others and flattering others in order to be liked by others. There are contradicting views regarding ingratiation. For instance, individuals are often viewed as dishonest and unlikeable if they show behaviour such as flattery (i.e. typical form of ingratiation) (Kim, LePine, \& Chun, 2021; Parker \& Parker, 2017). On the other hand, eliciting ingratiatory behaviour may lead to positive outcomes such as career advancement, receiving job offers, higher performance evaluations (Bolino, Varela, Bande, \& Turnley, 2006; Higgins, Judge, \& Ferris, 2003; Kim et al., 2018; Zhao \& Linden, 2011).

\section{Practical implications}

All employees want to maintain a positive image of themselves towards their colleagues and management in the workplace (Kondalkar, 2009). Management can be misled by employees when they use IM tactics to set a positive image of themselves, and therefore supervisors need to be informed about the IM tactics displayed by employees (Jackson, Schuler, \& Werner, 2011). If the organisation explores and familiarises themselves with the IM tactics desired and displayed by the employees from different cultures, it would contribute to management having a better understanding of employees from different cultural groups. By conducting the current study, organisations are provided with an opportunity to understand different behaviours that the Afrikaans Coloured culture elicits in the organisation. If the organisation explores and familiarises itself with the IM tactics desired and displayed by the employees from different cultures, it would contribute towards creating an organisational culture which is inclusive and where employees feel a sense of belonging. The findings of the research study will also guide the South African workforce to change their rationale on how they currently manage their employees' differences, needs and expectations of their company.

\section{Recommendations and limitations of the study}

It may be beneficial for superiors to undergo training in cross-cultural awareness specifically with regard to IM across different cultures. When there is an awareness amongst superiors regarding IM tactics displayed by cultural groups, decisions such as those relating to recruitment, selection and promotion will be unbiased and solely be based on objective measures. It may also be beneficial for the entire workforce to undergo cross-cultural awareness training in order to better understand the behaviours and motives of different cultures within the organisation.

No study goes without limitations. A small sample size was a limitation, and translating collected data back into English was also a limitation in this study. A larger sample size can be used in future. Although the goal of qualitative research is not to generalise because of the small numbers, it may be beneficial to interview more participants within the Afrikaans Coloured cultural group. Furthermore, by using 
triangulation, for instance, interviews and focus groups, richer information regarding the IM tactics of this cultural group can be collected.

\section{Conclusion}

The objective of this study was to explore IM tactics individuals in the Coloured culture display to impress people in the formal sector, like the work setting. A number of IM tactics were evident from the results of this study. Tactics used to impress both superiors and colleagues are to be hardworking and to display professional behaviour. Tactics used to impress colleagues only are being a good colleague and be true to yourself. Tactics used to impress superiors only include raise your opinion and display your uniqueness. Various tactics are used by this cultural group to impress both superiors and colleagues. It is evident that IM tactics are used in the formal setting by individuals in the Coloured culture to be seen in a positive light.

\section{Acknowledgements Competing interests}

The authors declare that they have no financial or personal relationships that may have inappropriately influenced them in writing this article.

\section{Authors' contributions}

L.D. developed the research proposal, collected, captured and analysed the data and wrote the manuscript. N.D.P.M. acted as the supervisor and L.R. acted as the co-supervisor of the study; both supervisors assisted with the proposal development, data analysis and provided feedback on the manuscript.

\section{Funding information}

This research received no specific grant from any funding agency in the public, commercial or not-for-profit sectors.

\section{Data availability}

Raw data collected for this study are presented on Excel documents. The collected and reported data are presented using unique identifiers under the results section.

\section{Disclaimer}

The views and opinions expressed in this article are those of the authors and do not necessarily reflect the official policy or position of any affiliated agency of the authors.

\section{References}

Adhikiri, M. (2008). From narratives of miscegenation to post-modernist re-imagining Toward a historiography of coloured identity in South Africa. African Historical Review, 40(1), 77-100. https://doi.org/10.1080/17532520802249472

Amineh, R.J., \& Asl, H.D. (2015). Review of constructivism and social constructivism. Journal of Social Sciences, Literature and Languages, 1(1), 9-16.

Anjum, M., \& Shah, S.Z. (2017). Indirect effects of FNE and POP on emotional exhaustion: The role of facades of conformity. Business \& Economic Review, 9(2), 225-254. https://doi.org/10.22547/BER/9.2.10
Bolino, M.C., Varela, J.A., Bande, B., \& Turnley, W.H. (2006). The impact of impressionmanagement tactics on supervisor ratings of organizational citizenship behavior. Journal of Organizational Behavior, 27, 281-297. https://doi.org/10.1002/job.379

Bolino, M., Long, D., \& Turnley, W. (2016). Impression management in organizations: Critical questions, answers, and areas for future research. Annual Review of Organizational Psychology and Organizational Behavior, 3, 377-406. https://doi. org/10.1146/annurev-orgpsych-041015-062337

Bott, E., \& Spillius, E.B. (Eds.). (2014). Family and social network: Roles, norms and external relationships in ordinary urban families. New York, NY: Routledge.

Bourdage, J.S., Wiltshire, J., \& Lee, K. (2015). Personality and workplace impression management: Correlates and implications. Journal of Applied Psychology, 100(2) 537. https://doi.org/10.1037/a0037942

Brouer, R.L., Gallagher, V.C., \& Badawy, R.L. (2016). Ability to manage resources in the impression management process: The mediating effects of resources on job performance. Journal of Business and Psychology, 31(4), 515-531. https://doi. org/10.1007/s10869-015-9426-5

Bryman, A., \& Bell, E. (2015). Business research methods (4th ed.). New York, NY: Oxford University Press.

Cable, D.M., \& Kay, V.S. (2012). Striving for self-verification during organizational entry. Academy of Management Journal, 55(2), 360-380. https://doi.org/10.5465/ amj.2010.0397

Choi, B.K., Moon, H.K., \& Chun, J.U. (2015). Impression management motive and voice: Moderating effects of self-monitoring, self-efficacy, and voice instrumentality. Asian Journal of Social Psychology, 18(3), 225-235. https://doi.org/10.1111/ajsp.12095

Clegg, S.R., Kornberger, M., \& Pitsis, T.S. (2016). Managing \& organizations: An introduction to theory and practice (4th ed.). Los Angeles, CA: SAGE Publications.

Creswell, J.W. (2014). Research design: Qualitative, quantitative and mixed methods approaches (4th ed.). Thousand Oaks, CA: Sage.

David, E.M., Kim, T.Y., Farh, J.L., Lin, X., \& Zhou, F. (2021). Is 'be yourself' always the best advice? The moderating effect of team ethical climate and the mediating effects of vigor and demand-ability fit. Human Relations, 74(3), 437-462. https:// doi.org/10.1177/0018726719894054

De Vos, A.S., Strydom, H., Schulze, S., \& Patel, L. (2011). The sciences and the professions. In A.S. De Vos, H. Strydom, C.B. Fouché, \& C.S.L. Delport (Eds.) Research at grassroots: For the social sciences and human services profession (pp. 3-26). Pretoria: Van Schaik.

De Wet., A. (2016). Exploring the influence of training and development on work engagement in a tertiary educational institution in South Africa. Masters dissertation. Potchefstroom: North West University.

Dondolo, V., \& Chinyamurindi, W.T. (2018). Impression management within the recruitment interview: Narratives of employees at a South African higher education institution. SA Journal of Industrial Psychology, 44, a1547. https://doi. org/10.4102/sajip.v44i0.1547

Edmonds, A.C., \& Besieux, T. (2021). Reflections: Voice and silence in workplace conversations. Journal of Change Management, 21(3), 269-286. https://doi.org/ 10.1080/14697017.2021.1928910

Feldman, Y. (2011). The complexity of disentangling intrinsic and extrinsic compliance motivations: Theoretical and empirical insight from the behavioural analysis of law. Washington University Journal of Law Policy, 35(1), 1-42.

Foxcroft, C., \& Roodt, G. (2013). Introduction to psychological assessment in the South African context (4th ed.). Cape Town: Oxford University Press.

Gardner, W.L., \& Martinko, M.J. (1988). Impression management in organizations. Journa of Management, 14(2), 321-338. https://doi.org/10.1177/014920638801400210

Gwal, R. (2015). Tactics of impression management: Relative success on workplace relationship. The International Journal of Indian Psychology, 2(2), 37-44. https:// doi.org/10.25215/0202.064

Higgins, C.A., Judge, T.A., \& Ferris, G.R. (2003). Influence tactics and work outcomes: A meta-analysis. Journal of Organizational Behavior, 2, 89-106. https://doi. org/10.1002/job.181

Holtgraves, T. (2004). Social desirability and self-reports: Testing models of socially desirable responding. Personality and Social Psychology Bulletin, 30, 161-172. https://doi.org/10.1177/0146167203259930

Hussain, S. (2018). Managing communication challenges in multicultural organizations. International Journal of Media, Journalism and Mass Communications (IJMJMC) 4(2), 44-49. https://doi.org/10.20431/2454-9479.0402005

Ibarra, H. (1995). Race, opportunity, and diversity of social circles in managerial networks. Academy of Management Journal, 38(3), 673-703. https://doi. org/10.5465/256742

Jackson, S.E., Schuler, R.S., \& Werner, S. (2011). Managing human resources. Mason, $\mathrm{OH}$ : South-Western

Jones, E.E., \& Pittman, T.S. (1982). Toward a general theory of strategic selfpresentation. In J. Suls (Ed.), Psychological perspective on the self (pp. 231-262). Hillsdale, NJ: Erlbaum.

Kemp, T. (2013). An exploration of social desirability within the white Afrikaans group. Master's thesis. Potchefstroom: North-West University.

Kim, J.K., LePine, J.A., \& Chun, J.U. (2018). Between a rock and a hard place: Contrasting upward and downward effects of leaders' ingratiation. Personnel Psychology, 71, 495-518. https://doi.org/10.1111/peps.12267

Kondalkar, V.G. (2009). Organisation effectiveness and change management. New Delhi: PHI Learning.

Korzynski, P., Haenlein, M., \& Rautiainen, M. (2021). Impression management techniques in crowdfunding: An analysis of Kickstarter videos using artificial
intelligence. European Management Journal, 39(4), 675-684. https://doi. org/10.1016/j.emj.2021.01.001 
Larson, K., \& Bradshaw, C. (2017). Cultural competence and social desirability among practitioners: A systematic review of the literature Children and Youth among practitioners: A systematic review of the literature. Children and Youth
Services Review, 76, 100-111. https://doi.org/10.1016/j.childyouth.2017.02.034

Leary, M.R., \& Tangley, J.P. (2012). The self as an organizing construct in the behavioral and social sciences. Handbook of Self and Identity, 15, 3-14.

Malham, B.P., \& Saucier, G. (2016). The conceptual link between social desirability and cultural normativity. International Journal of Psychology, 51(6), 474-480. https:// doi.org/10.1002/ijop.12261

Martin, G.C. (2014). The effects of cultural diversity in the workplace. Journal of Diversity Management (JDM), 9(2), 89-92. https://doi.org/10.19030/jdm.v9i2.8974

McCluney, C.L., Durkee, M.I., Smith, R., Robotham, K.J., \& Lee, S.S.L. (2021). To be, or not to be ... Black: The effects of racial code-switching on perceived professionalism in the workplace. Journal of Experimental Social Psychology, 97, 104199.

McQuerrey, L. (2019). Professionalism in a small-business office. Retrieved from https:// smallbusiness.chron.com/importance-professionalism-business-2905.html

Melloni, G., Stacchezzini, R., \& Lai, A. (2016). The tone of business model disclosure: An impression management analysis of the integrated reports. Journal of Management \& Governance, 20(2), 295-320. https://doi.org/10.1007/s10997-015-9319-z

Merdin, E. (2011). Self-marketing for graduates and professionals as a strategic career management tool. The Business Review, 19(1), 104-109.

Morris, M., Leung, K., Ames, D., \& Lickel, B. (1999). Views from inside and outside: Integrating emic and etic insights about culture and justice judgment. Academy of Management Review, 24(4), 781-796. https://doi.org/10.2307/259354

Mtshelwane, D. (2015). Exploring social desirability within the Zulu culture: An emic perspective (Unpublished master's mini-dissertation). North-West University, Potchefstroom

Neergaard, M.A., Olesen, F., Anderson, R.S., \& Sondergaard, J. (2009). Qualitative description the poor cousin of health research? BMC Medical Research description the poor cousin of health research? $B M C$
Methodology, 9, 52. https://doi.org/10.1186/1471-2288-9-52
Nieuwenhuis, J. (2016). Analysing qualitative data. In K. Maree (Ed.), First steps in research (pp. 26-47). Pretoria: Van Schaik.

Palmer, F.T. (2015). Through a coloured lens: Post-apartheid identity amongst coloureds in KZN. Doctoral dissertation. Bloomington, IN: Indiana University.

Parker, D., \& Parker, M.L. (2017). Sucking up: A brief consideration of sycophancy. Charlottesville, VA: University of Virginia Press.

Pratt, M.G., Rockmann, K.W., \& Kaufmann, J.B. (2006). Constructing professional identity: The role of work and identity learning cycles in the customization of identity among medical residents. Academy of Management Journal, 49(2), 235-262. https://doi.org/10.5465/amj.2006.20786060

Rebello, C.J., Burton, J., Heiman, M., \& Greenway, F.L. (2015). Gastrointestinal microbiome modulator improves glucose tolerance in overweight and obese subjects: A randomized controlled pilot trial. Journal of Diabetes and its Complications, 29(8), 1272-1276. https://doi.org/10.1016/j.jdiacomp.2015.08.023

Roberts, L.M. (2005). Changing faces: Professional image construction in diverse organizational settings. Academy of Management Review, 30(4), 685-711. https://doi.org/10.5465/amr.2005.18378873

Saxena, A. (2014). Workforce diversity: A key to improve productivity. Procedia Economics and Finance, 11, 76-85. https://doi.org/10.1016/S2212-5671(14)00178-6

Scott, S. (2019). The importance of professionalism in business. Retrieved from https:// smallbusiness.chron.com/importance-professionalism-business-2905.html

Spong, A., \& Kamau, C. (2012). Cross-cultural impression management: A cultural knowledge audit model. Journal of International Education in Business, 5(1), 22-36. https://doi.org/10.1108/18363261211261737

Statistics South Africa (StatsSA). (2019). Home page. Retrieved from http://www. statssa.gov.za/

Zhao, H., \& Liden, R.C. (2011). Internship: A recruitment and selection perspective. Journal of Applied Psychology, 96, 221-229. https://doi.org/10.1037/a0021295 